\title{
Development of Domestic Gas Supply and Utilisation Prices for Effective Gas Distribution in Nigeria
}

\author{
Kenneth Nduka, Ubanozie Julian Obibuike, Ifeanyi Michael Onyejekwe, Anthony Kerunwa, \\ Stanley Toochukwu Ekwueme
}

Department of Petroleum Engineering, Federal University of Technology, Owerri, Nigeria

Email address:

stanleyekwueme@yanoo.com (S. T. Ekwueme)

\section{To cite this article:}

Kenneth Nduka, Ubanozie Julian Obibuike, Ifeanyi Michael Onyejekwe, Anthony Kerunwa, Stanley Toochukwu Ekwueme. Development of Domestic Gas Supply and Utilisation Prices for Effective Gas Distribution in Nigeria. International Journal of Oil, Gas and Coal

Engineering. Vol. 9, No. 2, 2021, pp. 17-23. doi: 10.11648/j.ogce.20210902.12

Received: May 7, 2021; Accepted: May 27, 2021; Published: June 16, 2021

\begin{abstract}
Every resource produced by a country should by necessity satisfy the needs and demands of its populace before consideration is made for export. This will ensure that a country is sufficient in production and allocation of its resources. While Nigeria is regarded internationally as a major gas producer in the world, her local consumption of natural gas is limited due to unavailability of gas for domestic utilisations fuelled by large margins between domestic and international pricing of natural gas. At the international markets, the gas attracts higher price due to market conditions while the prices are relatively lower at the domestic level probably due to limited routes of utilisation of the resource. Because of this, gas producers prefer to sell their commodity at the international market creating scarcity at the local levels. This has heralded underdevelopment of the manufacturing sector and indigenous companies in Nigeria that thrive on natural gas. This situation can be ameliorated by developing a gas price model for effective utilization and distribution of gas in Nigeria. The model will determine the optimum price that producers should sale their gas to make profit and also make gas available locally. In this study, emphasis is made on the development of a domestic gas supply and utilisation price model for effective gas distribution in Nigeria. The model incorporates the cost of producing a unit volume of gas by the gas producer, the energy value of the gas and the quantity of the gas demanded locally. The model is based on the gas produced, utilised, flared, domestic gas requirement and the aggregate price of gas produced for the various companies. Results show that the total revenue accruable from flare is $\$ 1.877 \mathrm{~B} / \mathrm{yr}$ which is higher than the total revenue accruable from DGSO deficit which is $\$ 0.595 \mathrm{~B} / \mathrm{Yr}$. Thus, it is better that companies resort not to flaring. Analysis of the results also shows that companies are provided incentive by the model which closes gas deficit gap through a reduction in gas penalty price. Therefore, it serves as direct incentives to companies who meet with their DGSO. The results show that the gas deficit and flare penalty price has a direct impact on the flare penalty.
\end{abstract}

Keywords: Gas Supply Price, Gas Master Plan, Gas Volume, Gas Processing, Gas Production

\section{Introduction}

Natural gas streams comprises of chiefly methane with fractions of other higher molecular mass hydrocarbons present with some impurities. The mole percentage of methane is usually the highest while the composition of the natural gas depends on the source of the gas [1].

In the past, natural gas was seen as a waste product of oil production when in association with the produced oil. Because no use was there for it and due to lack of gas containment and utilisation technologies, associated gas was flared. Non-associated natural gas from dry gas wells were seldom drilled except in rare cases where there was viable and available markets. The situation has greatly changed in recent times, natural gas is now gaining dominance in the energy sector and by far surpassing oil in the fossil fuel value chain. This is because natural gas being more abundant is more pollution free and environmentally friendly when burnt. In a nutshell, natural is seen as the bridge fuel between the fossil fuel energy source and alternative energy sources [2].

Nigeria has more than 202 trillion cubic feet of gas as at 2019 [3]. This volume of gas as reserves is enough to transcend Nigeria as a major gas producer and user. The abundant gas reserve in Nigeria has prompted the Federal government of Nigeria to identify means to increase the 
development of the domestic gas sector with view to achieving increase in GDP. Natural gas is termed 'domestic' when it is utilised in-country that is to say within the shores of Nigeria. This utilisation could be for industrial, power, commercial, lighting in homes etc [4, 5]. Natural gas utilisation in the industrial sector spans across many areas such as methanol fertiliser, petrochemical, paper, etc [6].

Although government receives huge financial returns through the export of natural gas which come through tax receipts, and dividends but the domestic utilisation of natural gas provides greater benefits other than economic rent. These include value creation, job creation and multiplier effects. It becomes pertinent that Nigeria seek ways to develop its domestic gas sector as this will foster accelerated growth of other sectors dependent on energy and power [7].

The reason why many operators choose to sell their gas outside Nigeria is the rising gas price in the international market. This is the main driver behind the increased focus in liquefied natural gas (LNG) projects $[8,9]$. This has created an imbalance between the gas exported and that utilised domestically as there is great continual reduction in the gas set aside for domestic utilization [10-12]. This increasing reduction volumes of gas supplied for domestic utilisation hampers the developmental vision of Nigeria and may graduate to a case of domestic gas scarcity which may result to industrial shutdowns owing to lack of natural gas feedstock as raw materials. It is unwise that a country supports the development of other nations without having plans for its own development $[13,14]$.

Unfortunately, most of the gas produced in Nigeria is sold abroad at the international market rather than locally because the price index at the international market is higher than the local prices of the gas. This has made natural gas to be unavailable to meet up with local demands in the country. As result of this, local usage for natural gas is hampered hindering economic growth and leading to under-developed gas projects in Nigeria [15].

Meanwhile, the domestic demand for gas in Nigeria has drastically increased in the last two decades. Presently, total demand (export and domestic) for natural gas is by far higher than its supply. Gas is demanded for cooking, for heating, for lighting and industrially for power generation, fertilizer manufacturing, petrochemicals and manufacture of transport fuels such as GTL fuels and CNG fuels used in automobiles [16]. This rising growth in demand of natural gas has to be substantiated by provision of adequate quantities of gas by gas producers for local utilization. There is great need for the
Nigeria gas sector to prove itself capable in providing gas reliably and affordably else the companies that seek our gas may be force to shift to other nations whose gas sector are more stable and reliable like Egypt, Trinidad etc. Gas pricing is principally affected by the scale of demand relative to supply, this may create problem of gas availability which directly impacts on price affordability and pricing [17-19].

To achieve this, appropriate pricing models must be developed for the gas to compete with what the producers would have sold it abroad. This becomes the very essence of this work in developing a model for gas utilisation prices for effective domestic gas distribution in Nigeria.

\section{Methods}

In the methods, a mathematical model is developed for gas supply price to achieve effective gas utilisation in Nigeria. In this part, we develop the generalized price model for Domestic gas supply obligation.

When the main objective of a gas business is to stop natural gas flaring, then gas would be available free to any person or corporate body that shows the capacity to dispose the gas or utilize it without flaring. This explains why many gas producing nations make provisions for incentives geared towards pioneering gas utilization projects. Associated gas is produced at relatively very low cost. This is because the oil production covers most of the cost incurred in the production history.

One of the essences of Gas Master Plan is to make gas affordable to the consumers and at same time create an attractive environment for the investors. The investors would prefer to export this gas to meeting up with the DGSO and this is because the price at Henry Hub is much higher than what will be obtainable from the domestic market. Therefore there is need to create a balance between domestic affordability of gas and the export price of gas.

Government gave an aggregated price for the gas producing companies. The aggregated price was directly proportional to the average cost of producing a MSCF of gas by gas supplying companies. It was the summation of products of individual company price and their volume supply to the total volume of gas supplied by all the company. To determine the aggregated price, the average cost of producing a MSCF of gas by gas supplying companies must be known. Let $\mathrm{Cg}$ be the average cost of producing a MSCF of gas,

$$
\text { Cost of producing Mscf of gas }=\frac{\text { total cost of producing a certain volume of gas }}{\text { certain volume of gas, } D_{n}}
$$

The total cost of gas production for company $n$, is the total cost of investment (i.e. summation of the CAPEX, OPEX, Interest on loan $\left(I_{n}\right)$, fiscal Cost $\left.F c_{n}\right)$ on a ROI.

$$
\begin{aligned}
& \text { The total cost ofgas production for company } n \text {, on aROI }=\left(\text { capex }+ \text { opex }+I_{n}+F c_{n}\right) \times \text { ROI } \\
& \text { Cost of producing a MSCF of Gas on a ROI in } \$ / M S C F=\frac{\left(\text { capex }+ \text { opex }+I_{n}+F c_{n}\right) R O I}{D_{n}}
\end{aligned}
$$

The capital expenditure (CAPEX) includes: Concession acquisition, Exploration, Field studies, Drilling Facilities,
Production facilities, Gas gathering system, Processing/ Dehydration Plants, Transmission to Gas Plant, Transmission 
to Commercial Consumer, Commercial consumer facilities, and Distribution facilities. It also includes Processor CAPEX which considers: Gas Plant, LNG storage barges, Barge Towin, Tank-age system, Export facilities.

The operating expenditure (OPEX) is basically facility maintenance which could be either Quality reactive or Nonquality reactive. Quality reactive includes: Furnace maintenance, Pipeline and piping maintenance, flow assurance. Non-quality reactive includes: Production Bonus, Transmission tariff, Distribution operations, Consumables (utilities, logistics, HSE) and Human Resources.

The fiscal cost $\left(F c_{n}\right)$ includes: Royalty rate, Tax Rate, Capital Allowance, Consolidation Capital, Value Added Tax (VAT), Import duties, Levies, Dividend Withholding Tax (WHT).

Product quality will affect the gas pricing in two distinct notable areas: the level of impurities in the gas which is usually described as the sourness of the gas due to the presence of acid gases in the gas stream, this relates to how corrosive the gas is and the level and cost of treatment to reduce the contaminants to acceptable levels. The next factor is the product yield of the gas depending on the molar compositions of its constituents. Gas of different molar composition will yield different volumes of products like NGL, LNG, LPG, GTL etc. Lean gas (with high percentage composition of methane in the stream) will yield higher LNG but lesser LPGs and condensates. Conversely, rich gas (gas with higher percentage compositions or higher molecular mass hydrocarbons like propane, butane, pentane in the gas stream) will yield lesser LNGs and comparatively higher LPGs and condensates (which sales at higher unit prices because of higher calorific value). Thus, the prices of the rich gases are higher because of higher compositions of useful components in the gas stream.

The quality of gas differs and should affect the company's value for cost of gas produced. The natural gas produced comes on stream with other constituent that reduces the energy value. Lean gas has lower energy value than Rich gas. The energy value expressed in terms of the number of BTU (British thermal unit) per cu $\mathrm{ft}$ or in Joules, ranges from 1050 to $2220 \mathrm{BTU}$ per cu $\mathrm{ft}$.

Therefore,

$$
\text { Cost ofproducing MSCFofgas on a } R O I=\frac{\text { total cost ofproducingacertainvolumeofgasonaROI }}{\text { certain volume of gas }} \times \frac{\text { energyvalu eofgasproduced }}{\text { energy value of absolute methane gas }}
$$

Note: The cost of producing a MSCF of gas is the same as the price of gas. The price of gas for company n,

$$
\left(K_{n}\right)=\frac{\text { total cost of producing a certain volume of gas by company } \mathrm{n},\left(\mathrm{C}_{\mathrm{n}_{\mathrm{ROI}}}\right)}{\text { certain volume of gas by company } \mathrm{n},\left(\mathrm{D}_{\mathrm{n}}\right)} \times \frac{\text { energy value of gas produced by company } \mathrm{n},\left(\mathrm{J}_{\mathrm{n}}\right)}{\text { energy value ofabsolute methane gas, }\left(\mathrm{J}_{M}\right)}
$$

$$
K_{n}=\frac{C_{n_{R O I}}}{D_{n}} \times \frac{J_{n}}{J_{M}}
$$

Where, $J_{M}$ is the energy value of methane in BTU/cu- $\mathrm{ft}$, and $J_{n}$ is the energy value of gas produced by company $n$.

Also, $C_{n}$ is the total cost of producing a certain volume of gas by company $\mathrm{n}$. The reference gas quality for the given grade of gas is obtained from Gas Processors Suppliers Association handbook (GPSA) specifications or from contractual agreements. The volume of gas was assumed at standard temperature and pressure (STP), and the effect on Gas quality presented in the Appendix (GPSA). Alternatively, mass unit can be used where available.

The aggregated price $\left(K_{A}\right)$ model in $\$ / T C F$, can be formulated through product averaging as;

$$
K_{A}=\frac{D_{1} \times K_{1}+D_{2} \times K_{2}+\cdots+D_{n} \times K_{n}}{\sum_{i=1}^{n} D_{n}}=\frac{\sum_{i=1}^{n} D_{n} \times K_{n}}{\sum_{i=1}^{n} D_{n}}
$$

$K_{n}$ Is individual company price in $\$ / \mathrm{TCF}$

Note:

$$
K_{n}=K_{A} \text { (assuming uniform company price } K_{n} \text { ) }
$$

Gas price depends on the degree of maturity of the market. Early enough when the capital investment in the gas project has not been realized, the cost of gas would be relatively high because all the expenditures would be included into the cost of the gas. However, subsequently the investment cost of the gas project would be recovered. During this time there is full depreciation of the cost of installation, thus, need for elimination of installation cost and adjustment of the gas supply cost. To assure market maturity there should be availability of gas at an affordable rate that will encourage investors and the consumers. To achieve this simplified objective we have to adjust our aggregated price, to accommodate the Henry Hub price $\left(K_{H H}\right)$, the consumer aggregated floor price $\left(K_{A_{C}}\right)$ and the producer aggregated price $\left(K_{A}\right)$ and thereby producing a correlation that will determine our adjusted aggregated price, $K_{A A}$.

Using product averaging method;

The adjusted aggregated price

$$
K_{A A}=\frac{K_{A} \times D_{T}+K_{H H} \times D_{E}+K_{A C} \times D}{D_{T}+D_{E}+D}
$$

$D_{T}$ is the total gas produced for sale (volume of gas exported $\left(D_{E}\right)$ and the volume of gas obligated $\left.(D)\right)$.

The Henry Hub price varies at different energy value, the consumer aggregated floor price,

$K_{A_{C}}$, is the summation of the product of domestic sector floor prices and their respective volume to their total volume.

$$
K_{A_{C}}=\frac{P_{S} \times K_{P}+M_{S} \times K_{M}+C_{S} \times K_{C}}{D\left(=P_{S}+M_{S}+C_{S}\right)}
$$

Where $P_{S}, M_{S}, C_{S}$ is the volume of gas consumed by the power sector, manufacturing sector and the commercial sector respectively in MSCF. Likewise, $K_{P}, K_{M}$ and $K_{C}$ are the floor prices of the power sector, manufacturing sector and the commercial sector respectively, in \$/MSCF.

The penalty price $\left(K_{P_{n}}\right)$ for company n, not meeting up to the DGSO was made a function of the aggregated price $\left(K_{A}\right)$ 
and the percentage constraints, limiting the company from achieving their obligated gas supply. Therefore, the Penalty price equation becomes,

$$
K_{P_{n}}=K_{A A}(1-\text { constraints } \%)
$$

The constraints could be as a result of the following factors:

i. Fluctuation in price at the international market. If the price of export gas was not stable and leaps more than the OPEC price. Gas producers may work out the economics and chose not to supply at full capacity. And to even choose to pay a penalty instead of achieving their domestic gas obligated supply.

ii. The cost of production: This includes cost of lease acquisition and maintenance, cost of exploration, cost of gas production up to separator, production lines cost, facility operational cost, gas processing cost, cost of gas storage and shipment to central hub. If the cost of production per MSCF of gas is greater than the income from gas sells, the gas producers may go back to their economics to see if it is better for possible way out.

iii. Market maturity: a situation whereby the gas supplier is not too sure of the rate of return due to market quandary, it may result to laxity in getting up to DGSO.

Fiscal terms: funding of gas project is financially enormous and the intricacies associated with fund raising could hinder the company in pooling in their gas quota.

For the specific purpose of providing a numerical solution to the penalty price, the constraint percent need to be quantified. This was done by expressing the constraint percent in terms of quantity of gas supplied $\left(D_{n_{i}}\right)$, to their domestic gas supply obligation $\left(D_{n}\right)$. The penalty price equation becomes;

$$
K_{P_{n}}=K_{A A}\left(1-\frac{D_{n_{i}}}{D_{n}}\right)
$$

This implies that the higher the gas deficit $\left(D_{n}-D_{n_{i}}\right)$, the higher the penalty price. when $D_{n_{i}}=0$, then the penalty price $\left(K_{P_{n}}\right)$ would be the same as the aggregated price $\left(K_{A A}\right)$.

This model therefore provides an incentive to companies that close the gas deficit gap and directly encourages companies to meet up with the DGSO.

The model development for gas flare penalty price $K_{F P} n$ for company $\mathrm{n}$ shall put into consideration the aggregated gas price $\left(K_{A A}\right)$, the volume of gas produced by a company $\left(P_{n}\right)$ and the volume of gas flared by a company $\left(F_{n}\right)$

Factors considered include the following:

The penalty price should be zero with no flared gas

The gas flare regulated policy should be establish to pull in flexibility

The percentage of flared gas if higher, then the flare penalty price, then the flare penalty price should be increased so operators would be on their toes to achieve flare down.

The gas flare penalty should not be more than the aggregated gas price, such that it would accommodate the cost of harnessing the gas.

With these factors in consideration, the simplified model:

$$
K_{F P_{n}}=K_{A A}\left(\frac{F_{n}}{P_{n}}\right)
$$

This model above assumed, the produced gas was equivalent to the sum of the flared gas and the utilised gas.

\section{Results}

The results from using the model developed for domestic gas supply and utilization prices are given below.

\subsection{Domestic Gas Supply Deficiency and Penalty Price}

The result in table 1 show that although some companies met their gas obligation there are still gas deficiency since many of the operators did not meet up with their obligation. If we maintain the aggregation price of $\$ 4.985 \mathrm{~B} / \mathrm{TSCF}$; assuming presently that the operating companies are supplying 30 percent of their produce and their DGSO requirement is $2.2 \mathrm{TCF}$ as at year 2010, we shall determine

\begin{tabular}{|c|c|c|c|c|c|c|}
\hline Company & $\begin{array}{l}\text { Gas Produced, } \\
P_{n}(\mathrm{TCF} / \mathrm{yr})\end{array}$ & $\begin{array}{l}\text { Domestic gas } \\
\text { supply, } \\
D_{n_{i}}(\mathrm{TCF} / \mathrm{yr})\end{array}$ & $\begin{array}{l}\text { Domestic gas } \\
\text { requirement, } D= \\
2.2(\mathrm{TCF} / \mathrm{yr})\end{array}$ & $\begin{array}{l}\text { Gas Deficit } \\
D_{n}-D_{I} \\
(\mathrm{TCF} / \mathrm{yr})\end{array}$ & $\begin{array}{l}\text { Penalty Price } \\
\text { Appreciation } \\
\text { Value, (1-Dni/Dn) }\end{array}$ & $\begin{array}{l}\text { DGSO Gas Penalty } \\
\text { Price, (\$/TSCF), } \\
\text { KA (1-Dni/Dn) }\end{array}$ \\
\hline SPDC & 2.2740 & 0.6822 & 0.91412 & 0.23192 & 0.25371 & 1.26476 \\
\hline $\mathrm{CNL}$ & 0.7780 & 0.2334 & 0.30149 & 0.06809 & 0.22585 & 1.12590 \\
\hline NAOC & 1.0375 & 0.3112 & 0.31212 & 0.00087 & 0.00280 & 0.01397 \\
\hline TOTAL/ELF & 0.9620 & 0.2886 & 0.27998 & -0.00861 & -0.03076 & 0.14875 \\
\hline ADDAX & 0.2260 & 0.0678 & 0.04678 & -0.02101 & -0.44916 & -2.23908 \\
\hline NPDC/AENR & 0.0453 & 0.0135 & 0.01555 & 0.00196 & 0.12652 & 0.63070 \\
\hline SNEPCO & 0.1404 & 0.0421 & 0.07195 & 0.02983 & 0.41464 & 2.06700 \\
\hline MONI-PULO & 0.0037 & 0.0011 & 0.00785 & 0.00674 & 0.85865 & 4.28040 \\
\hline CONSOLIDATEDOIL & 0.0007 & 0.0002 & 0.00246 & 0.00225 & 0.91467 & 4.55965 \\
\hline POOCN & 0.0810 & 0.0243 & 0.01504 & -0.00926 & -0.61536 & -3.06755 \\
\hline OTHERS & 0.0720 & 0.0216 & 0.07593 & 0.05433 & 0.71555 & 3.56705 \\
\hline Summation & 5.6257 & 1.6877 & 2.2 & 0.51229 & & \\
\hline
\end{tabular}
their penalty price template below.

Table 1. Domestic Gas Supply Deficiency and Penalty Price.

The analysis of the table indicates that this model provides an incentive to companies that close the gas deficit gap by reducing their penalty price. Therefore it serves as direct incentives to companies who meet with their DGSO. 


\subsection{The effect of the DGSO Deficit on the Penalty Appreciation Value}

The Penalty Appreciation Value (PAV) is heavily dependent on the difference between the gas supplied and actual domestic gas requirement. The Penalty Appreciation Value is the factor determining the penalty price which also directly affects the penalty revenue and the higher the PAV, the higher the Penalty Price and Revenue.

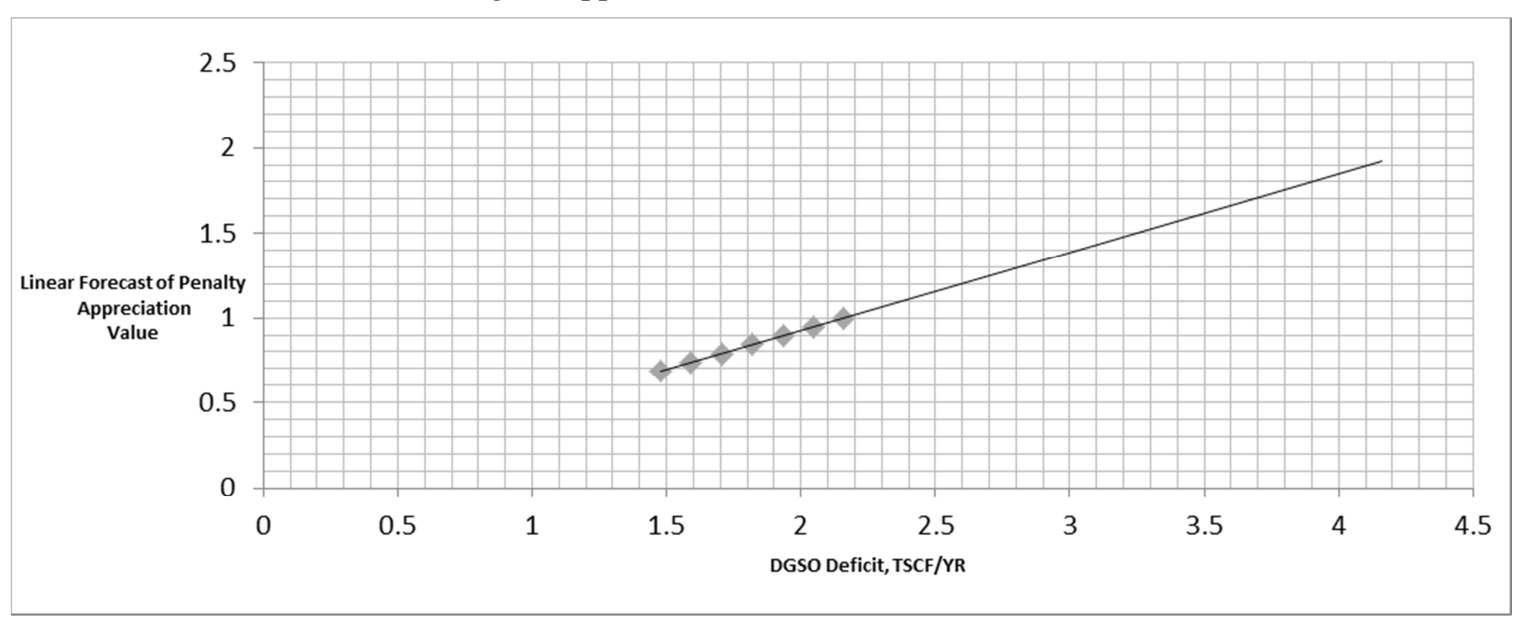

Figure 1. The effect of DGSO Deficit on the Penalty Appreciation Value.

The linear forecast of the Penalty Appreciation Value over the DGSO Deficit have shown an increase; implying that operators should work toward minimizing the gas deficit.

\subsection{The impact of the Gas Flare Penalty on the Revenue}

Operating companies might choose to flare this gas meant for use as the domestic gas supply obligation because the cost of processing of this gas may be enormous and decide to pay penalty for not meeting with the domestic supply obligation. But at the same time these operating companies will be paying penalty as a result of flare. The sum of these penalties will determine if it is economical to pay the penalty or to process this gas. Government has an arbitrary flare price which is based on the price of gas at Henry Hub with the exception of the cost of processing this gas. This project developed a model based on the gas produced, utilised, flare, domestic gas requirement and the aggregate price of gas produced which is mathematical displayed in equation 12 and 24. The template below shows the impact of the gas flare penalty model on the revenue.

Table 2. Impact of the gas flare penalty on the Price.

\begin{tabular}{|c|c|c|c|c|c|c|c|}
\hline Company & $\begin{array}{l}\text { Gas } \\
\text { Produced,(TCF } \\
/ \text { yr }), P_{n}\end{array}$ & $\begin{array}{l}\text { Flared, } \\
\text { TCF } / y r), F_{n}\end{array}$ & $\begin{array}{l}\text { Domestic gas } \\
\text { supplied, } D_{n_{i}} \\
(\mathrm{TCF} / \mathrm{yr})\end{array}$ & $\begin{array}{l}\text { Domestic gas } \\
\text { requirement, } D= \\
2.2(\mathrm{TCF} / \mathrm{yr})\end{array}$ & $\begin{array}{l}\text { Gas Deficit } \\
D_{n}-D_{I} \\
(\mathrm{TCF} / \mathrm{yr})\end{array}$ & $\begin{array}{l}\text { Flare Penalty } \\
\text { depreciation } \\
\text { Value, }\left(\frac{F_{n}}{P_{n}}\right)\end{array}$ & $\begin{array}{l}\text { Flare Penalty Price, } \\
(\$ / T S C F), K_{F P}=K A \\
\left(\frac{F_{n}}{P_{n}}\right)\end{array}$ \\
\hline SPDC & 2.2740 & 2.167 & 0.6822 & 0.914126 & 0.2319 & 0.9529 & 4.750437 \\
\hline MPNU & 0.0051 & 0.003 & 0.0015 & 0.156669 & 0.1551 & 0.6274 & 3.127843 \\
\hline CNL & 0.7780 & 0.604 & 0.2334 & 0.301496 & 0.0680 & 0.7763 & 3.870102 \\
\hline NAOC & 1.0375 & 0.585 & 0.3112 & 0.312125 & 0.0008 & 0.5638 & 2.810819 \\
\hline TOTAL/ELF & 0.9620 & 0.417 & 0.2886 & 0.279988 & -0.0086 & 0.4339 & 2.163448 \\
\hline NPDC/AENR & 0.0453 & 0.044 & 0.0135 & 0.015558 & 0.0019 & 0.9867 & 4.918973 \\
\hline SNEPCO & 0.1404 & 0.014 & 0.0421 & 0.071956 & 0.0298 & 0.1011 & 0.504180 \\
\hline MONI-PULO & 0.0037 & 0.003 & 0.0011 & 0.007853 & 0.0067 & 0.8108 & 4.041891 \\
\hline CONSOLIDATEDOIL & 0.0007 & 0.000 & 0.0002 & 0.002461 & 0.0022 & 1 & 4.985000 \\
\hline POOCN & 0.0810 & 0.077 & 0.0243 & 0.015043 & -0.0092 & 0.9506 & 4.738827 \\
\hline OTHERS & 0.0720 & 0 & 0.0216 & 0.075938 & 0.0543 & 0 & 0 \\
\hline Summation & 5.6257 & 4.135 & 1.6877 & 2.2 & 0.5122 & 0.7350 & 3.664072 \\
\hline
\end{tabular}

The summary of the table shows that the gas deficit and flare penalty price has a direct impact on the flare penalty. Also that the revenue accruable is highly appreciative and this model should be commended in the sense that it is dynamic and sensitive in giving incentives to operators that has done well in achieving its domestic gas obligation. Under the same consideration, the total revenue accruable from flare is $\$ 1.877 \mathrm{~B} / \mathrm{yr}$ which is higher than the total revenue accruable from DGSO deficit which is $\$ 0.595 \mathrm{~B} / \mathrm{Yr}$.
Therefore, companies should do everything possible not to incur this liability.

\subsection{Comparison between DGSO Penalty Price and Flare Penalty Price for the Operating Companies}

Under the same conditions of considerations, the price at which companies will pay for not meeting up with the DGSO and the Price at which they will pay for flaring a volume of gas that would have been used to meet with the domestic 
supply obligation is comparable. It could be seen that the prices vary for different operating company; if the general gas flare/produce is high and the quantity of DGSO gas flare is low then the Flare Penalty Price will be higher than the
DGSO Penalty Price as in the case of ADDAX. Both Penalty price could be high if the general gas flare/produce and DGSO gas flare is high as in the case of consolidated oil.

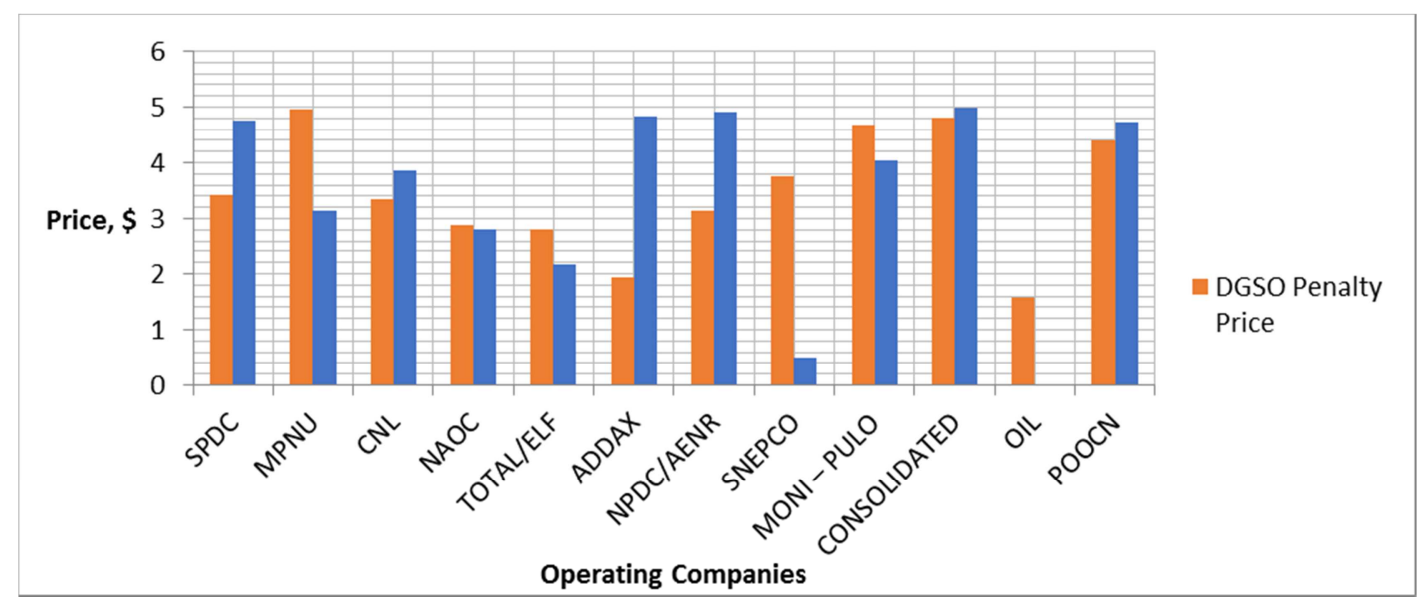

Figure 2. Comparison between DGSO Penalty Price and Flare Penalty Price for the Operating Companies.

\section{Conclusion}

This work determines what price gas is to be sold locally to make sure that there is availability of gas for domestic utilization. A mathematical model was developed which incorporates the gas produced, utilised, flared, domestic gas requirement and the aggregate price of gas produced for the various companies. The implementation of the model will help in the development of gas projects in the country as more gas would be available for domestic utilisation. The model also set penalties for flaring, this is done to discourage gas producers who may wish to flare their gas rather than processing and making it available for domestic utilisation. In general, the domestic gas supply price model when implementation in the natural gas sector will improve the standard of living of the citizens of Nigeria through myriads of functional gas projects made possible by gas availability through the pricing model developed. Thus, the model is highly recommended for use in the allocation of price of natural gas in the Nigeria natural gas sector.

\section{References}

[1] Malcolm, B. (2004), "The vital role of gas in a sustainable energy future", paper presented at CERA conference, Houston.

[2] Kupolokun, F. (2005), Growth Projection for Nigeria's gas sector. An article published in the Nigerian Guardian, 9th may, Lagos.

[3] Nigeria National Petroleum Corporation (NNPC). (2019). Annual Statistical Bulletin.

[4] Oyewunmi, Tade (2015) 'Natural Gas Exploration and Production in Nigeria and Mozambique: Legal and Contractual Issue 13 (1) OGEL Journal 1.

[5] Kazeem L. A., Amam, S. and Yang, J. (2006), "Between Gas Flare-out and Sustainable Oil and Gas TS2" Gas Utilization
"SPE 105963, presented at 30th Nigerian Annual International Conference and Exhibition held in Abuja, Nigeria.

[6] OyewunmiTade, Iwayemi Akin (2016) Gas Supply to Power Markets in Nigeria: A Regulatory and Economic Assessment. The 9th NAEE/IAEE International Conference, Abuja Nigeria.

[7] Morgan L. and Chinwo, C. N. (2006), "Sustainable Gas Utilisation and the Clean Development Mechanism: The Nigerian Perspective" SPE 105968, presented at 30th Nigerian Annual International Conference and Exhibition held in Abuja, Nigeria.

[8] Emejulu, O, FUTO Consult Nigeria Ltd, (2009), "Development of Gas Aggregation and Allocation Models in the Domestic Sector of the Economy" A paper presented at Gas Stakeholders Forum in Abuja.

[9] Neeka, B. J, MPR Nigeria, (2010), "Gas Aggregation and Allocation in the Domestic Sector of the Economy" A paper presented at Gas Stakeholders Forum in Abuja, 15th February.

[10] Nduka K., Anyadiegwu C. I., Duru, U. I., Obibuike, U. J., Ekwueme, S. T (2020). "Development of Domestic Gas Supply Obligation Model for Efficient Gas Utilisation in Nigeria", International Journal of Oil, Gas and Coal Engineering.

[11] Nduka, K., Obibuike, U. J., Udechukwu, M., Mbakaogu, C. M., Igbojionu, A. C., Ekwueme, S. T. (2020).“Development of Revenue Model for Optimum Gas Distribution and Utilisation in Nigeria", International Journal of Oil, Gas and Coal Engineering.

[12] IkeanyibeOkechukwu Marcellus (2020). "Managing postprivatisation challenges: a review of Nigeria's electricity sector", Journal of Contemporary African Studies.

[13] Okerie, G. A, (2009), "Economic Sustainability of Gas for domestic growth" publication on Oil and Gas Journal (OGJ).

[14] Imoudu P. B. and Igbatayo, S. A. (2006), "Developing Nigeria's Gas Industry for Regional Economic Integration: The West African Gas Pipeline Project" SPE 105967, presented at 30th Nigerian Annual International Conference and Exhibition held in Abuja, Nigeria. 
[15] Okparaojiaku, O. C, DPR Nigeria (2008), "Domestic Gas Supply Obligation Status" A paper presented at Gas Stakeholders Forum in Lagos.

[16] Prasad V. S. N. Tallapragada, (2009). 'Nigeria's Electricity Sector- Electricity and Gas Pricing Barriers'. First Quarter IAEE Energy Forum, 29-34.

[17] Ogwo, U. J. O, DPR Nigeria, (2007), "Equitable Gas Pricing Model" SPE 111897, presented at 31st Nigerian Annual
International Conference and Exhibition held in Abuja, Nigeria.

[18] Ogwo, U. J. O, DPR Nigeria, (2008), "A Survey of Existing Gas Prices and Tariff Models in Nigeria" A paper presented at Gas Stakeholders Forum in Abuja.

[19] Ogwo A. E, PetroGas Ltd, (2010), "Instruments for the Implementation of Domestic Gas Supply Obligation" A paper presented at Gas Stakeholders Forum in Lagos, 24th February. 